\title{
Early pregnancy diagnosis by echotomography in the sow
}

\author{
Françoise MARTINAT-BOTTE *, O. BOTERO *, F. BARITEAU ** \\ *Institut Technique du Porc, 149, rue de Bercy, 75595 Paris Cedex 12 \\ **I.N.R.A., Station de Physiologie de la Reproduction, \\ Nouzilly, 37380 Monnaie
}

It was previously demonstrated in a small number of sows that ultrasonic echography may be used in the diagnosis of pregnancy (BOTERo et al., 1984). The present work was made to confirm this hypothesis.

A total of 2257 presumably pregnant sows of different breeds and parieties were scanned between 18 and 90 days after insemination. The scanning instruments used were a SAL $22 \mathrm{~A}$ and a SAL $32 \mathrm{~A}$ Toshiba real-time B-scope with a probe of $3.5 \mathrm{Mhz}$. The procedure for examination and interpretation of the pictures was that previously described (Botero et al., 1984). Diagnosis was checked on the basis of the farrowing date and of the number of born piglets in pregnant sows, and by return to oestrus in non-pregnant ones. The accuracy of the diagnosis was calculated according to the physiological stage. It reached 93.1 p. 100 for 2257 scans. In pregnant sows the accuracy was better after Day 21 than earlier (99.6 vs 96.6 p. 100). The errors mainly occurred between Day 18 and 21 and in sows having further littered less than 5 piglets.

In non-pregnant sows the accuracy was lower, but different cases have to be considered. When diagnosis was performed early (18-25 days) and before normal return to oestrus, accuracy ranged around $75 \mathrm{p}$. 100 . It then decreased linearly to $50 \mathrm{p}$. 100 in case of late return to oestrus. On the other hand, after the 26th day post-insemination, the accuracy of the diagnosis varied between 70 and $80 \mathrm{p}$. 100 when the pregnancy test took place less than 20 days before return to oestrus. It fell to 60 p. 100 for returns occurring more than 40 days after examination.

The examination conditions are liable to affect the accuracy. Pregnancy diagnosis can be made from Day 20 after insemination when sows are tethered (93.3 p. 100) and 2 days later when they are immobilized in cubicles or in pens $(93.8$ p. 100). This technique is difficult to use when animals are not tethered in pens or reared outside, tethered or not. Besides, a training period is required for the operator. It may be concluded that echotomography is a reliable means of diagnosing gestation, but it can only be used from Day 20 to 22 post-insemination.

\section{Use of echotomography for diagnosing infertility}

\author{
Françoise MARTINAT-BOTTE *, O. BOTERO ** \\ * Institut Technique du Porc, 149, rue de Bercy, 75595 Paris Cedex 12 \\ **I.N.R.A., Station de Physiologie de la Reproduction, \\ Nouzilly, 37380 Monnaie
}

Echotomography enables to vizualize the uterus and its content and thus to make a pregnancy diagnosis. In the present study, this technique was used to detect cystic follicles or pyometritis in 41 sows culled for infertility. 
The day before slaughter, the animals were scanned and a photo was taken. After slaughter, genital tracts were collected and put into bags with individual sow identification. Examination of ovaries and uterus allowed to make a diagnosis of the status of the reproductive organs. These results were compared to the observations recorded during scanning. This gave rise to diagnoses of 9 cases of pregnancy, 19 cases of pregnancy without apparent abnormality and 13 cases of pathological abnormalities.

The accuracy of the diagnosis reached 92 p. 100 in sows without pathological abnormality or in pregnant ones. It was lower $(38.5$ p. 100$)$ in those exhibiting a pathological abnormality. Scanning showed that 3 sows out of 6 had very large cystic follicles (diameter $>25 \mathrm{~mm}$ ), and 2 out of 6 a pyometritis.

These preliminary results suggest that the diagnosis of more or less severe lesions of the genital tract will become more and more accurate as experience will be gained.

\title{
Communal rearing of the young within the social group of European wild boars
}

\author{
Isabelle DELCROIX *, I.P. SIGNORET **, R. MAUGET * \\ * Centre d'Etudes Biologiques des Animaux Sauvages (C.E.B.A.S./C.N.R.S.), \\ Villiers-en-Bois, 79360 Beauvoir-sur-Niort \\ ** I.N.R.A., Station de Physiologie de la Reproduction, \\ Nouzilly, 37380 Monnaie
}

The conditions of communal rearing of the young within the social group of European wild boars were studied in a group of six females and one male living in a wooded enclosure of 1 ha in the Chizé forest (Midwestern France).

Farrowing was recorded from early April to mid-July. Spontaneous adoptions of young occurred. They concerned three females, i.e. two which had farrowed simultaneously and a third one which had already been suckling for 21 days.

The sequence and duration of suckling were characterized. The behaviour leading to dietary independency settled parallel to suckling.

The social rearing context of the offspring was studied. The females rearing their young all together were in tight association. The different litters showed large affinities for all the mothers without any clearly selective relationships.

The absence of an early and exclusive mother-young bond seems to be in the favour of a communal care-taking of the young which in wild suids is based on the social group. 